Article

\title{
Research on Globalization Policies of Exchange Programs in Higher Education
}

\author{
Dr. Susan Hui-Yun Yang1 and Dr. Patricia Haseltine ${ }^{2}$ \\ 1 Minghsin University of Science and Technology; huiyunyang18@gmail.com \\ 2 Providence University; pathaseltine@gmail.com \\ * Correspondence: huiyunyang18@gmail.com; Tel.: 886-3-5873100
}

\begin{abstract}
Teachers of English as a foreign language in Taiwan are challenged to organize multidimensional language activities for foreign students coming from ASEAN countries, including Japan, the Philippines, South Korea, and Vietnam. With different cultural backgrounds, these students have different prior knowledge of Taiwanese culture, and, because of the similarities and differences between Taiwan and these countries, it is meaningful to explore the development of globalization with the students, who are learning both English and Chinese. The different historical backgrounds, various cultural and religious differences, and social conditions, such as gender relationships in working places, are significant topics for class discussions. When teachers serve as discussion facilitators, they encourage students to express their own multi-identities and expectations for the exchange program. Most interesting of all is to find out about their own shortterm and long-term career goals. 32 foreign students from the Philippines and Vietnam were recruited for research. Questionnaires were used to assess their foreign language learning motivation and strategies, as well as to discover the learning environment they prefer and their globalization prospects. It was found that multi-lingual language policies for promoting globalization in higher education are very likely to influence the success of foreign student study in Taiwan.
\end{abstract}

Keywords: higher education, exchange programs, Taiwan, ASEAN countries, globalization, localization

\section{Introduction}

As globalism has brought economic changes in Southeast Asia, educational institutions also provide support for New ASEAN Policies proposed by the Taiwan government. Internationalization is one of the important goals for universities, so branding is very important for them as they attempt to attract other universities' attention outside of Taiwan. The force for competition, innovation, and transformation have become the trend for them to develop their international sister bonds in order to look for more exchange students, who will help to globalize their institutions. Minghsin University of Science and Technology has constantly engaged in globalization efforts by developing its links with sister universities in many countries. It is well-known abroad for having positive relationships with business sectors around Taiwan, taking a leading role in organizing exchange programs and innovating a multi-lingual policy. In the past few years, educational exchanges between Taiwan and the Philippines, Vietnam, and Japan have increased through the efforts of better communication between colleges in these countries.

One of the obstacles to the increase in economic exchanges remains in the different languages that are spoken in different countries. Liddicoat points out that nowadays more universities focus on "the ideology of English as the lingua franca of commercial, cultural and educational life" [1] (p. 2). Sinner reveals the trend of universities in pursuing internationalization strategies and observes that 
the conflicts may have different levels of consequences at the national level. In Denmark, for instance, internationalization is facilitated by the use of English [2]. English is often used to facilitate the exchanges in Taiwan with other Asian countries; however, in the Taiwan universities and workplaces, Chinese is the main language of communication used, and many companies have cooperation with universities to recruit foreign students in the assembly line for making products. Therefore, courses in both English and Chinese are offered to exchange students. By sharing their resources and ability to speak more than one foreign language, these exchange students prepare themselves for many sectors of the economy and will be able to find employment in the changing global job market. Since English, which has become very much a lingua franca of globalism, is learned by students in all fields, when preparing exchanges, they may find that it is their proficiency in English that facilitates their communication.

Skills in using foreign languages in the past were a part of the history of colonialism in East Asia. Japanese colonization of Taiwan, French colonization of Vietnam and the Spanish colonization of the Philippines have exercised strong influences on the cultures, the architecture and the thought of these regions. Resistance to the rule of foreign powers remains a significant trait in most of these cultures. Southeast Asian countries have also been greatly influenced by World War II, which started in 1939 and ended in 1945. Black in the introduction to Volume III of The Second World War: Alliance politics and grand strategy reminds his readers that "the relationship between the war and its post-war is also a sphere that is more complex than references simply to the onset of the Cold War and the development of decolonization struggles might suggest" [3] (p. xix). However, in spite of these or due to these historical upheavals, receptivity to learning new languages brings an empowering attitude that the more successful individuals in business, as well as in technology, can use in their occupations as the Southeast and East Asian economies continue to thrive.

In Taiwan, where Chinese is spoken as a main language, students are required to learn English, and many feel burdened by having to learn this language since they do not use it in their everyday environment. Contrarily, foreign exchange students seem to be much more highly motivated. Since motivation of the students is of utmost concern by educators, how the coordinated efforts of several disciplines and teaching resources may be used in exchange programs is therefore an important area to research. Schumann, the author of The Neurobiology of Affect in Language, argues that second language acquisition is primarily emotionally driven and emotion underlies most, if not all, cognition [4]. Ushioda's theoretical framework of motivation from a temporal perspective provides a useful method to investigate the positive L2-learning experiences and match them with the learners' shortterm goals or even other life goals they have in their minds. This is quite significant since "motivational thinking integrates the phenomenon of evolution over time, which seems central to the learner's experience of and thus conception of language learning motivation" [5] (pp. 82-83). That is, life motivations dovetail with language-learning motivations.

Based on Dörnyei and Ottó's process model of L2 motivation [6], it is important to notice the action sequence of learners from their preactional phase, through the actional phase and then to the postactional phase. Investigating the action sequence, the researcher can figure out their motivational influences, such as goal setting, intention formation, and intention enactment in the first phase. Then in the second phase, their executive motivational influences can be studied. At last, the research may focus on postactional evaluation on how students form causal attributions, elaborating their strategies and even dismissing intention and further planning. Thus, motivation research represents 
multiple perspectives of learners' purposes of studying languages and culture and individual goals are crucial to the scope of decisions they make.

Doing research on learner autonomy, Pham and Hamid think that language teachers are not only facilitators who help their learners make decisions but also counsellors who respond to their learners' needs. They argue that in specific contexts, learner autonomy is "glocalised" at local universities [7] (p. 235). Studying in Taiwan, foreign exchange students have their own prior knowledge about learning languages, so language teachers should not only encourage their learners to express their own ideas but also be innovative in doing curricular planning with administrators.

Ahamer recommends that quality assurance in transnational higher education requires "a peeroriented procedure involving assessors, lecturers, practitioners and university administration on an equal basis in a culture and atmosphere of collaboration" [8] (p. 1304). Similarly, Higgins and Brady propose complexity of language policies that are carried out on several levels: on a micro-level, a macro-level and even the institutional level. Thus, they think that local contexts of policy-makers and planners "realistically, practically, and particularly respond to macro level calls, whether implied or directly stated, to connect these new ways of language study to globalization and internationalization of higher education efforts" [9] (p. 27). At the basic level, the teacher not only must cooperate with national and university policies, but also carry out research that will contribute to the success of transnational exchange programs in the context of globalization in Asia.

\section{Materials and Methods}

Several open-ended questionnaires were distributed to study the motivations of Philippine and Vietnamese students for studying English and Chinese languages and to evaluate their experiences of living and studying in Taiwan. The results of a likert-scale questionnaire, which was given to about $1 / 3$ of the exchange students at Minghsin University of Science and Technology, is also used in this study to assess the effects of Taiwan's globalization policies, the foreign language learning strategies students use, their attitudes toward the learning environment, and their career expectations. The main purposes of the research were to discover how their national backgrounds, their language study, and their goals related to their motivations.

First of all, 11 Filipino exchange students studying in the Mechanical Engineering Department at Minghsin were recruited for research. They had a good background in the English language, and by using English, they were taking a Chinese History and Culture class. Thus, the teacher, the primary researcher for this paper, was able to do cross-cultural research on the development of globalization at Minghsin University of Science and Technology (MUST). These students were not only active but also enthusiastic in joining in school activities, such as English singing contests and Christmas celebrations and parties. They were eager to study Chinese language and culture. It was found from their responses that, besides language, they are also highly interested in studying body language among Taiwanese college students. While staying in Taiwan to study not only in their professional field, these exchange students, who majored in mechanical engineering got involved in cultural contacts with the local students and people in the Hsinfeng area. They also were studying Chinese classes at MUST. Since few people in the local area could communicate in English, the culture course, along with their study of the Chinese language, served as a cultural mediator, facilitating the increased global awareness of the participating students. 
Secondly, the other group studied was composed of 21 Vietnamese students. They were encouraged by their government to apply for the study at MUST. Most of them were from northern Vietnam, with a few from the central or the southern areas. They studied and worked as interns in local companies in order to pay for their tuition. The Vietnamese students were diligent, friendly and social. They studied Chinese for communication with Chinese college students at MUST and local people in the neighborhood or even their colleagues in the working environment. They are good at communicating with the people around them. They are only required to study Chinese for one semester, but must take English for two years. There were many cultural difference between the two groups of students. For example, in comparison with the Vietnamese students, the Filipino participants were all Christian. They reported that they worshipped God, asking to be led in their study and careers. They prayed together, thankful for being given peace, courage, and happiness. They sometimes went to a church nearby to join in the mass. Most of the Vietnamese students stated that they worshipped their ancestors, so they adhere to Taoist beliefs. There talked about the many temples in their hometowns. Besides their ancestors, they also worship some Gods and Goddesses. It is clear that the Vietnamese are more similar to the Taiwanese students than the Filipino students in their belief system.

The research methodology therefore mainly employed class observation, interviews, openended questionnaires on cultural differences and globalization, as well as the results of a likert-scale questionnaire on students' language learning strategies and interests. Responses for the open-ended questionnaires were received in writing in English. The likert-scale questionnaire was distributed online in English and in Vietnamese. In a series of class discussions in English, students also were guided to share their own family background information, ethnic identities, life goals, and expectations for their career. They were willing to tell their own stories in the classes.

\section{Results}

This study investigated the motivation of exchange students for learning foreign languages, both English and Chinese. Through observation, the primary researcher recorded that ASEAN students who were engaged in their exchange in Taiwan, tended to adapt themselves well to the new learning environment. Being conscious of Taiwanese culture, they were constantly transforming themselves in order to enjoy learning at Must University of Technology. It was found that most of them have an avid interest in learning foreign languages in general, as well as learning more English and Chinese, in contrast to native Taiwanese students required to study English in EFL courses. The exchange students were able to discuss problems of history and society. It is not only part of their career advancement goals, but also sustains their generally positive attitude toward foreign language and culture education. As for learning Chinese, their interest compares favorably with their motivation to study English although it is new experience for most of them. Although they only were taking Chinese lessons for one semester, some of them said they would like to have more Chinese courses if it's possible. Others, who were able to take more Chinese, demonstrated that they had learned Chinese characters, idioms, and even pragmatic usages of some high frequency phrases. The teacher who served as facilitator encouraged them to express their own multi-identities and expectations in the exchange program. The most interesting aspect of all was to discover their career plans, which included both their short-term and long-term goals. 
The data from questionnaires on foreign language learning strategies, the learning environment and globalization policies distributed to 32 foreign students from the Philippines and Vietnam was analyzed to determine how to carry out educational innovation for exchange students at MUST. Under the dual degree program, all of the Filipino students can concentrate on their study for 2 years at MUST. They have to apply for an internship in a company at the end of 2019. After the internship, they have to go back to their college in their home country for completing their degree. Filipino students are active in participating in all kinds of activities and contests. They make a lot of foreign friends from different ASEAN countries at MUST. Since English is their second language, they say they enjoy speaking English with their teachers in class. Especially they like to sing Chinese and English songs for special occasions. Their answers on the open-ended questionnaires show that they really enjoy studying and living at MUST. All the Filipino students showed that it is positive for them to study in Taiwan for they can not only study Chinese but also strive to receive a Washington Accord Diploma at the end of their college education. Some also participated in the 2019 Smart Global Drive Automation Competition. They received three awards in this competition. With high motivation in the study of mechanical engineering, they are highly satisfied with the exchange program, with learning advanced technology, and are eager to know more about Chinese culture. After graduation, they hope to apply for jobs in Taiwan because they enjoy living in a multi-cultural environment. The exchange program is quite successful for they gain more confidence in themselves as engineers.

In the first year, the Vietnamese students have to concentrate on their study, and then they find a part-time job after they get the work permission from the government. They have to get used to balancing the study and work style they will use for about 3 years. Most of them do not expect to make return visits to Vietnam while they study and work in Taiwan. Although they have homesickness, they can't go back home because they need to save their money. Although they have such factors as religious belief in common with Taiwanese students, they feel that the local Taiwanese students are not willing to make friends with them. In the working environment, they have to speak Chinese in order to communicate with their bosses or colleagues. Most of them hope that they can study more Chinese at MUST, and a few of them would like to study more English for their career development.

Encountering cultural differences, the Filipino students think that Chinese students are quite gentle. On the contrast they like to express their emotion by singing songs in public. Their body language is quite rich in comparison with the local students and Vietnamese students. They think that reading Chinese novels and stories will be very helpful for them to have an in-depth understanding of the Chinese culture and beliefs. In the questionnaire specifically, most of them replied that they would like to read stories in order to learn more and agree that studying foreign languages every day is the most important thing for them to do in order to upgrade their foreign language proficiency level. Most of the participants in these two groups think that they will continue to study more Chinese for their career and are willing to study more foreign languages if possible.

\section{Discussion}

In order for teachers of English and culture to understand their distinctive role in the ASEAN policy-guided exchange programs on the university level, it is beneficial to focus on the three phases of language learning suggested by Dörnyei \& Ottó. Educators in countries of exchange can start from 
their learners' preactional phase, get deeply involved in the actional phase and help students form strategies for the postactional phase. In the first phase, the goal setting stage, intention formation and enactment are important in the overall plan of exchange. Since globalization in Southeast Asian countries has been influenced by previous colonization and the outcome of WW II, the relations between the nations from which our exchange students come is based on previous relationships in this area of the world. The factors of globalization policies based on geopolitical factors of history of the respective governments play a large part in determining the course of the exchanges in our study. How students are chosen to engage in these programs is a part of the globalization effort of each country before they come to Taiwan.

Before their contact with the foreign culture, exchange students understand and express their own national and local identities. With respect to identity, Liu points up cultural differences. She thinks that even "nurseries are a good indicator of how individuals express their identities" [12] (p. 92). She points out that the values of individualism and group-orientation are the main difference among the westerners and Taiwanese people. Thus, where a person comes from will influence the course of their exchange. When students come to Taiwan, they are also acting out their own self-identity, which may also involve a local identity they have held in their native country. It is clear that local identity does play an important role in education. For example, Storry \& Childs take examples of mythic figures to discuss British identities, such as "Britannia, Albion, John Bull, and the heroes of Arthurian mythology and other folk stories" [10] (p. 19). Storry reveals education is different from training by saying that "the former comes from the Latin word educo meaning to lead out or develop qualities which are within" and "training is to do with the supply of workers, and is not concerned with the individual" [11] (p. 94).

Language teachers in exchange programs in Taiwan are primarily involved in the second phase, the actional phase. In this phase, motivational influences are extremely important and need to be studied thoroughly. Cultural education is an important part of exchange programs that involve both training and education, especially in the case of students coming to Taiwan to study. Although they intend to engage in work training programs in their technological fields, they also hope to enjoy learning about Chinese and Taiwanese culture, too.

Exchange students can be seen as primarily interested in cultural tourism. As the results of this study show, students from the Philippines and Vietnam are highly motivated for their foreign language study because they do see how it will benefit them socially. Since, while they are in Taiwan, they are also tourists to some extent, the materials used in the classes are very important and need to address the problem of overturning stereotypes. Lohmann, Netto, \& Rodrigues mention that stereotypes of destinations may be either positive or negative by the results of magazines, newspapers, websites or gossips among friends or people in different communities. Furthermore, in the marketing campaign for specific destinations, they suggest that potential visitors require "adequate infrastructure, attractions and quality services" [13] (p. 212). Hocaoglu does research on the development of cultural tourism by focusing on city identities for "culture is the main element that shapes the image of the city and is a crucial component in city promoting campaigns" [14] (p. 236). Tourists and business networks are related to the city branding strategies. Thus the analysis on the features of Hsinchu, where 
Minghsin is located, is very important for attracting exchange students and keeping them motivated in their wish to communicate in Chinese while in Taiwan.

At last, the research may focus on postactional evaluation on how our exchange students form strategies for furthering their careers. Thus, motivation research represents multiple perspectives of learners' purposes of studying languages and culture, but the end result of the language study is a part of their overall career goal. .

\section{Conclusion}

This research on the backgrounds and motivation of exchange students from the Philippines and Vietnam in a university in Taiwan has uncovered the complexity of the programs in their present stage of development. Peters points out three forms of the knowledge economy: the learning economy, the creative economy and the open knowledge economy. The knowledge economy leads the promises of open education. New communication and information technologies help language learners study foreign language effectively [15]. The foreign students come to Taiwan from different countries with different policies of globalization, and each student has a different life story, but they are all deeply engaged in the search for all these forms of the knowledge economy in Southeast Asia.

As a teacher of English to exchange students from Japan, the Philippines, and Vietnam, the primary researcher for this study found that motivation for learning foreign languages with exchange students is higher than for the local students in Taiwan. Perhaps it is because the foreign students see a reason for their efforts to learn the language and are undergoing a concrete experience in a foreign culture. And for students coming to Taiwan, it is also deemed useful for them to be able to learn the foreign language of Chinese, even though it requires the learning of a new writing system. In accordance with Ahamer's recommendation for achieving quality assurance, Chinese and English Language Education Centers in Taiwan should work with the Academic Affairs Department to create the right multi-lingual curricular policies for both the foreign and local Taiwanese students. More policies should be activated in order to promote the cultural communication modes between different groups of students from different countries. Furthermore, it is important to have meetings with other administrators in universities in Taiwan and abroad.

Interdisciplinarity is an important factor in the success of exchange programs. Higgins and Brady think that local contexts of policy-makers and planners "realistically, practically, and particularly respond to macro level calls, whether implied or directly stated, to connect these new ways of language study to globalization and internationalization of higher education efforts" [16] (p. 27). A variety of perspectives in different fields are to be used. In our study, the efforts of the university administration in setting up the programs with different countries are coordinated with the school's connections to the business sector and with the resources of several departments. The areas of the students' main study, like mechanical engineering or service industries, are coordinated with their study of foreign languages, both English and Chinese. The language teachers in exchange programs should understand and apply a knowledge of the different cultural and educational backgrounds of the students and their local identities. These teachers should also give attention to their differing needs and desires in their students' language study in order to maintain the motivation required for their success not only in the exchange program, but also in their future careers in the globalized world. 
Author Contributions: The primary author, Dr. Susan Hui-yun Yang, was the English language and Chinese Culture teacher for the exchange students at Minghsin University of Science and Technology (MUST). She was responsible for the overall conceptualization of the study and distributed the questionnaires to her students. She designed the methodology, carried out the investigation, analyzed and wrote about the results. This work complements her previous research on motivation among English as a Foreign Language (EFL) students in Taiwan. Dr. Patricia Haseltine, the second author, assisted in the formation and conceptualization of the questionnaires, provided background information on resources in multicultural education, and assisted in the editing of the manuscript. Both authors have read and agreed to the published version of the manuscript.

Funding: This research received financial support from a Taiwan Ministry of Education fund distributed by the Academic Affairs Section of Minghsin University of Science and Technology.

Conflicts of Interest: The authors declare no conflict of interest.

\section{References}

1. Liddicoat, A. J. Language policy and planning in universities: Teaching, research and administration. In Language policy and planning in universities: Teaching, research and administration; Liddicoat, A. J., Ed.; Routledge: Oxon, UK, 2018; pp.1-11.

2. Sinner, M. University administrators as forced language policy agents. An institutional ethnography of parallel language strategy and practices at the University of Copenhagen. In Language policy and planning in universities: Teaching, research and administration; Liddicoat, A. J., Ed.; Routledge: Oxon, UK, 2018; pp. 240257.

3. Black, J. Introduction. In The Second World War. Volume VII. Alliance politics and grand strategy; Black, J., Ed.; Ashgate Publishing: Hampshire, UK, 2007; pp. xi-xx.

4. Schuman, J. H. The neurobiology of affect in language. Blackwell: Oxford, UK; 1998.

5. Ushioda, E. Effective motivational thinking: A cognitive theoretical approach to the study of language learning motivation. In Current issues in English methodology; Soler, E. A., Espurz, V.C., Eds.; Universitat Jaume I: Castelló de la Plana, Spain, 1998; pp. 77-89.

6. Dörnyei, Z.; Ottó, I. Motivation in action: A process model of L2 motivation. Working Papers in Applied Linguistics (Thames Valley University, London) 1998, 4: 43-69.

7. Pham, T. T. H.; Hamid, M. O. Learner autonomy in foreign language policies in Vietnamese universities: An exploration of teacher agency from a sociocultural perspective. In Language policy and planning in universities: Teaching, research and administration; Liddicoat, A. J. Ed.; Routledge: Oxon, UK; 2018; pp.222239.

8. Ahamer, G. Quality assurance in transnational education management: The developmental "global studies" curriculum. In Information resources management association curriculum design and classroom management: Concepts, methodologies, tools, and applications; Information Resources Management Association; IGI Global: Hershey, PA, USA, 2015; Vol. 3, pp. 1271-1313.

Higgins, R. M.; Brady, A. Language policy, planning, and enactment: The necessity and empowering potential at the local level. In Language policy and planning in universities: Teaching, research and Administration; Liddicoat, A.J., Ed.; Routledge: Oxon, UK, 2018; pp. 12-29.

9. Storry, M.; Childs, P., Eds. British cultural identities. Routledge: London, UK, 1997.

10. Storry, M. Education, work and leisure. In British cultural identities; Storry, M., Childs, P., Eds.; Routledge: London, UK, 1997; pp. 83-127.

11. Liu, A. C. Taiwan A to Z: The essential cultural guide. $4^{\text {th }}$ print. The Community Services Center: Taipei, Taiwan, 2013.

12. Lohmann, G.; Netto, A. P.; Rodrigues, C. B. Tourism destination images. In Tourism theory: Concepts, models, and systems, Lohmann, G., Netto, A. P. Eds.; CABI: Oxfordshire, UK, 2017. pp. 211-213.

13. Hocaoglu, D. Challenges in promoting cities through culture within the new global economy. In Global place branding campaigns across cities, regions, and nations; Bayraktar, A., Uslay, C. Eds.; IGI Global: Hershey, PA, USA, 2017; pp. 229-250. 
14. Peters, M. A. Three forms of the knowledge economy: Learning, creativity and openness. In Handbook on globalization and higher education; King, R., Marginson, S., Naidoo, R., Eds.; Edward Elgar Publishing, Inc.: Northampton, MA, USA, 2001; pp. 76-94.

15. Higgins, R. M.; Brady, A. Language policy, planning, and enactment: The necessity and empowering potential at the local level. In Language policy and planning in universities: Teaching, research and administration; Liddicoat, A. J. Ed.; Routledge: London, UK, 2018; pp. 12-29. 